\title{
Impacto de las migraciones en Chile. Nuevos retos para el pediatra. ¿Estamos preparados?
}

\author{
RODRIGO VÁSQUEZ-DE KARTZOW ${ }^{1}$ \\ 1. Pediatra Infectólogo, Profesor Asistente, Departamento de Pediatría y Cirugía Infantil Campus Centro, Facultad de \\ Medicina Universidad de Chile.
}

\begin{abstract}
Impact of migrations in Chile. New challenges for the pediatrician. Are we prepared?

Migrations are a worldwide phenomenon, where in South America Chile has become a receiving country of immigrants. The arrival of foreigners to the country, besides being a necessity due to local demographic changes with tendency of investment of the population pyramid, it can cause local epidemiological changes, presenting unknown diseases and increasing others controlled by monitorization epidemiological programs. In Chile, $1.3 \%$ of the population are foreigners, mainly becoming from countries like Peru, Argentina, Bolivia, Ecuador, Colombia and recently Palestine. $11.8 \%$ of immigrants are younger than 14 years-old, where $40 \%$ of them are not enrolled in the Public Health System and $30 \%$ do not have identification card. A period of latency of 6 months is estimated since the illegal entry to the country until it is incorporated to the National Health System. General doctors and pediatricians must be prepare for rare diseases in the country.

(Key words: migrations, epidemiological changes, foreigner).

Rev Chil Pediatr 2009; 80 (2): 161-167
\end{abstract}

\section{RESUMEN}

Actualmente las migraciones son un fenómeno mundial. En América del Sur, Chile se ha convertido en un país receptor de inmigrantes. La llegada de extranjeros al país, a demás de ser una necesidad por los cambios demográficos locales con tendencia a la inversión de la pirámide poblacional, puede ocasionar cambios epidemiológicos locales, presentando enfermedades desconocidas y aumento de otras controladas gracias a los programas de vigilancia epidemiológica. En Chile, el 1,3\% de la población es extranjera, principalmente provenientes de países como Perú, Argentina, Bolivia, Ecuador y Colombia y más recientemente de Palestina. El 11,8\% de los inmigrantes son menores de 14 años de edad. Se estima que cerca del $40 \%$ de estos niños inmigrantes no se encuentran inscritos en el Sistema de Salud Pública y de estos, el

Trabajo recibido el 01 de enero de 2009, devuelto para corregir el 02 de marzo de 2009, segunda versión el 13 de marzo de 2009, aceptado para publicación el 16 de marzo de 2009.

Correspondencia a:

Dr. Rodrigo Vásquez-De Kartzow

E-mail: rvasquezk@gmail.com 
$30 \%$ no tiene cédula de identidad. Se considera que existe un período de latencia de aproximadamente 6 meses desde el ingreso ilegal al país hasta que es atendido en el Sistema Nacional de Salud. Los médicos generales y pediatras debemos prepararnos para la atención de niños inmigrantes quienes pudieran tener enfermedades poco conocidas en el país.

(Palabras clave: migraciones, cambios epidemiológicos, extranjeros).

Rev Chil Pediatr 2009; 80 (2): 161-167

"La medicina de la inmigración no es una medicina de parásitos ni virus raros. ES medicina de hombres y mujeres que se diferencian en la forma de expresar su sufrimiento, su modo de concebir la enfermedad, el acto médico, el dolor o la muerte. De unos hombres y mujeres que han dejado una cultura sanitaria sin haberla abandonado $y$ adquieren otra sin todavía comprenderla, de unos enfermos que esperan de nuestro mundo sanitario una tecnología carismática que los salve, pero que no aciertan a hacer comprender sus problemas interiores a médicos y cuidadores"

R. Colasanti. En: II Congreso de Medicina y Emigración. Roma, 1990.

El fenómeno de las migraciones en el mundo es tan antiguo como su historia. Desde la aparición en la Tierra del Homo habilis hace 2,5 millones de años ${ }^{1}$, constantemente el Ser Humano se ha desplazado de un lugar a otro en busca principalmente de mejores condiciones para él y su tribu; donde obtener comida, abrigo y un sitio para refugiarse. Ello no es muy diferente de lo que ocurre en la actualidad, donde la migración interna (dentro del mismo país de origen) y la migración externa (fuera del país de origen) alcanza hoy por hoy cifras alarmantes. Se estima que cerca de 200 millones de personas ( $3 \%$ de la población mundial) viven en un país distinto al de su nacimiento o lo que es lo mismo, 1 de cada 35 personas en el mundo es inmigrante internacional ${ }^{2}$. A medida que pasan los años esta situación se va incrementando, así por ejemplo, en la década del 70 dicha población alcanzaba los 82 millones, en el año 2000 se estimaba en 175 millones y para el año 2005 se sobrepasó la cifra de 200 millones de inmigrantes ${ }^{3}$.
En América Latina y el Caribe hay más de 20 millones de personas que residen fuera de su país natal ${ }^{4}$.

\section{Factores que favorecen la migración}

Son múltiples las causas o factores que impulsan las migraciones de personas, siendo las principales, los factores económicos, la falta de trabajo, la violencia, terrorismo e inseguridad, el turismo, la búsqueda de bienestar social y la búsqueda de mejores condiciones de salud, entendiendo ésta última como el bienestar biopsico-social de las personas.

La movilización de personas más allá de sus fronteras trae consigo grandes impactos, positivos y negativos para el país que los recibe. Hay un aumento en la población y con ello cambios en la pirámide poblacional, lo cual en algunos casos es una ventaja, como en el caso de España, el cual se comentará más adelante. Lleva a cambios socio económicos y al aumento en la demanda de diversos bienes y servicios, tiende a producir el desplazamiento del empleo de la población autóctona, ya que generalmente los recién llegados se contratan por sueldos más bajos y condiciones más precarias, deteriorando así la estructura salarial en diferentes sectores. Además se presenta un aumento de la actividad informal, por ejemplo los vendedores ambulantes. Igualmente, y en el ámbito de la salud, el país que recibe a los inmigrantes puede estar en riesgo de sufrir cambios epidemiológicos en enfermedades erradicadas, controladas o incluso aquellas prevalentes pero con un patrón epidemiológico conocido.

Pero no todo es malo en la migración. Son varios los aspectos positivos que pueden dejar la incorporación de inmigrantes en una socie- 
dad, por ejemplo la expansión económica en el país receptor y en el de origen ya que al generar mejores ingresos, los inmigrantes envían remesas a su país de origen, que para el caso de Latinoamérica, alcanzó los US\$ 32000 millones de dólares, además del riquísimo intercambio cultural que surge de la convivencia con cada uno de los grupos de foráneos ${ }^{5}$.

\section{Algunas experiencias a través del mundo}

El grueso de la población en Europa se considera envejecida, con una tasa de natalidad muy baja y una sobrevida cada vez mayor, lo que ha llevado a una inversión de la pirámide poblacional. En países como Alemania, el 9\% de la población es extranjera. En Francia alcanza el 6\% y en España la población inmigrante corresponde al 4,7\% de la población total. Precisamente en este último país, España, con una población extranjera de 1.984.573 habitantes, con la tasa de natalidad más baja de Europa y cada vez mayor sobrevida, se enfrentan a una inversión de la pirámide poblacional, estimando que para el año 2050, de continuar la tendencia, tendrían una proporción de 1,4 personas activas por cada jubilado, siendo lo ideal la proporción de 4-5 activos por 1 jubilado. De no corregirse esta situación, el Estado no será capaz de sostener a una, cada vez mayor, población de personas adultas jubiladas. En Chile, de no existir una intervención adecuada, podría tenerse una proyección similar en la pirámide poblacional.

Todo esto favorece y estimula las migraciones como un factor positivo para tratar de mejorar esta situación.

Las migraciones en América Latina se caracterizan por tener 2 tipos de patrones, migraciones de ultramar, que predominaron desde fines del siglo XIX y principios del siglo XX, proveniente principalmente de Europa y las migraciones intra-regionales explicadas por variaciones económicas y políticas, principalmente.

La situación en Chile, según el censo poblacional de 2002, mostró que existía una población extranjera de 195320 habitantes, correspondiendo al 1,3\% del total de habitantes en el país, de los cuales 23150 personas son meno- res de 14 años $^{6}$. Chile se ha considerado fundamentalmente un país de emigrantes aunque, desde hace algunos años, esta tendencia ha ido cambiado, convirtiéndose en un país receptor de migrantes debido, fundamentalmente, a temas de seguridad social, estabilidad económica y mejores condiciones para surgir comparado con los demás países de la región.

La población extranjera de Chile es principalmente proveniente de América del Sur, siendo los países más frecuentes, Perú en un $26 \%$, Argentina en 23\%, Bolivia en 6\% y Ecuador en $5 \%$. Recientemente se ha visto una tendencia a la feminización de la migración, principalmente en la población peruana. El $70 \%$ de las mujeres, la mayoría entre los 15 y 44 años, trabajan en el servicio doméstico y $20 \%$ de ellas tienen estudios técnicos y universitarios ${ }^{6}$ (figura 1).

Según los análisis demográficos, en Chile se está presentando una situación similar a la que ocurre en Europa, con una mayor población perteneciente a la tercera edad y una tasa de natalidad que ha disminuido considerablemente en los últimos 10 años, pasando de 20,5/1 000 habitantes en 1994 hasta 14,9/1 000 habitantes en $2004^{7,8}$. Todo esto hace suponer que, como se mencionó anteriormente, la pirámide poblacional sufrirá un cambio sustancial para el 2050, de no corregir las políticas poblacionales y de inmigración existentes hasta el momento.

\section{Población extranjera en Chile, 2002}
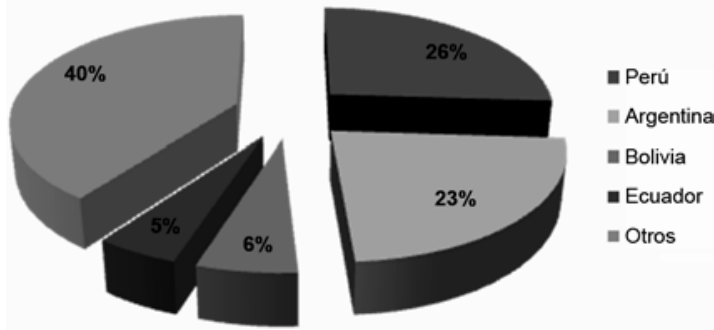

Figura 1. En Chile, en la última década ha habido un incremento exponencial en la población extranjera, siendo Perú el principal país de origen, seguido por Argentina, Bolivia, Ecuador y Colombia. Dentro del grupo "Otros" se encuentran principalmente venezolanos, paraguayos, uruguayos, brasileros, españoles y más recientemente palestinos. Fuente: INE. Censo 2002.Chile 


\section{Situación de algunos extranjeros en Chile}

Existen en nuestro país diferentes estudios de la población de inmigrantes desde el punto de vista sociológico pero pocos son los estudios con un enfoque epidemiológico y de salud de dichos inmigrantes.

En diciembre de 2005 se realizó en la Región Metropolitana una encuesta entre la población extranjera que reveló que el $40 \%$ de los niños inmigrantes no se encuentran inscritos en el Sistema de Salud Pública y mucho menos en una Isapre. De estos, el 30\% no tienen cédula de identidad, que es un requisito para ser atendidos en el sistema ${ }^{9}$. En Santiago, con algunas excepciones, se exige la presentación de la cédula de identidad para la atención en salud ${ }^{10}$.

Se ha estimado que existe un período de latencia de 6 meses entre que el extranjero, principalmente ilegal, ingresa al país y es atendido por primera vez en el Sistema Público de Salud. Ello ha llevado a que algunas instituciones como por ejemplo la Cruz Roja, haya convertido una de sus unidades de atención primaria, en atención casi exclusiva de extranjeros en situación irregular, principalmente de procedencia peruana ${ }^{11}$.

En un estudio sociológico realizado en 2007, se ha estimado que cerca de 3000 niños indocumentados, especialmente peruanos, bolivianos y ecuatorianos, no recibirían atención en salud como lo establece la Constitución y la Convención de los Derechos del Niño, de la cual Chile hace parte ${ }^{12}$.

El Estado de Chile reconoce como extranjero residente aquel individuo que tiene un contrato de trabajo, estudiantes temporarios, personas con asilo político o refugiados ${ }^{13}$. Hacia finales de 2007 existían cerca de 15000 extranjeros en el territorio nacional con situación irregular $^{12}$.

\section{Chile, país vulnerable}

Chile es un país que pudiera considerarse exitoso desde el punto de vista de la salud pública, con una tasa de desnutrición de $0,7 \%$, que al compararla con países vecinos como
Bolivia con $26 \%$ y Perú con $25 \%$ es definitivamente un avance importante en la salud de los chilenos. Con respecto a tuberculosis, tenemos una tasa, para 2006, de 14,2/100 000 habitantes que nos sitúa en etapa de eliminación de la enfermedad $^{14}$, y con la tasa más baja de Sur América. Por el contrario, Perú presenta un complicado escenario con una tasa de 155/ 100 000. En similar situación se encuentra Bolivia con una tasa de 113/100 000 habitantes. Otro ejemplo del éxito en la salud pública de nuestro país es la tasa de mortalidad infantil de 7,8 por 1000 nacidos vivos ${ }^{15}$ estando muy por debajo de lo encontrado en algunos países vecinos como Perú con 37, Bolivia con 66 y Argentina con 14,7 por 1000 nacidos vivos.

Todo lo anterior hace de Chile, hasta el momento, un país con grandes avances en cuanto al control de algunas enfermedades infecciosas, gracias en buena parte, a los programas de vigilancia epidemiológica y campañas de prevención impartidas por el Ministerio de Salud y demás organismos pertinentes.

Existen varios ejemplos en el mundo que demuestran la influencia que han tenido las migraciones en la epidemiología local, ocasionando un aumento o estancamiento en las tasas de infecciones.

Tal es el caso de España, con una de las tasas de tuberculosis más altas de Europa, alcanzando 20 casos/100 000 habitantes/año. La mayoría de estos casos son inmigrantes. Por ejemplo, en Barcelona, que es una de las regiones con mayor afluencia de inmigrantes, el porcentaje de extranjeros con tuberculosis ha aumentado del 5\% al 32\% con tasa de incidencia entre los inmigrantes por encima de 100 casos/100 000 habitantes ${ }^{16}$.

Un panorama similar se vive en Australia, país que tiene una de las tasas de tuberculosis más bajas del mundo y los pocos casos que se presentan son en refugiados extranjeros y en un grupo de pescadores inmigrantes ilegales. Esto ha puesto en riesgo la tasa de enfermedad y la aparición de cepas de Mycobacterium tuberculosis multiresistentes al tratamiento habitual $^{17,18}$

En Suiza, con una tasa menor a 10 casos/ 100000 habitantes, más del 60\% de los casos que se registran cada año afecta a la población 
inmigrante. En 2003 hubo 624 casos de tuberculosis en todo el país, de los cuales 338 eran inmigrantes. Según las estadísticas, 1 de cada 350 solicitantes de asilo en ese país está enfermo de tuberculosis. Esto ha llevado a la autoridad sanitaria a establecer la norma que todo solicitante de asilo debe tomarse como mínimo una radiografía de tórax ${ }^{19,20}$.

Otro ejemplo es lo que sucede en Beijing, donde la tuberculosis es una enfermedad infecciosa re-emergente y un sustancial problema de salud publica en la República Popular China. La proporción de casos de tuberculosis en la población migrante está aumentando año a año.

En el 2006, el 80\% de los casos se presentó en población migrante. En China la inmigración es predominantemente interna (dentro del mismo país $)^{21}$.

En Chile, tras alcanzar una tasa baja de tuberculosis (14,2/100 000 habitantes) desde 2005 , esta tasa no ha variado. Una de las explicaciones para ello puede ser por los casos presentados en población inmigrante, principalmente proveniente de Perú, Ecuador y Bolivia, aportando el 1,5\% de los $\operatorname{casos}^{14}$. Es de recalcar que hasta hace muy poco tiempo no era obligatorio informar el país de origen del paciente con tuberculosis. De hecho, aún no es requisito registrar la nacionalidad del paciente a su ingreso al hospital en la ficha de estadística. Aunque la cifra de $1,5 \%$ es baja, se debe considerar el subregistro por omisión de datos pertinentes.

Uno de los principales problemas de la infección por el Mycobacterium tuberculosis es la cada vez más frecuente resistencia a los diversos fármacos utilizados para el tratamiento. En los países industrializados el costo de la tuberculosis multiresistente puede sobrepasar los 100 mil dólares americanos por paciente. Un informe de la Organización Mundial de la Salud señala que existen 16 millones de casos de tuberculosis (TB) en el mundo, que cada año aparecen ocho millones de casos nuevos y mueren dos millones, constituyendo el mayor factor de mortalidad en las mujeres jóvenes. A pesar de eso, solamente el 16\% de casos infecciosos de tuberculosis en el mundo reciben el tratamiento recomendado por esa organización. Como siempre, es en el sector marginal de los pueblos donde las epidemias se ensañan debido al alto costo para su curación y es con frecuencia en este mismo sector que la enfermedad es resistente a los antibióticos conocidos, lo que la convierte en un mal incurable para aquellos que no tienen acceso a esos costosos tratamien$\operatorname{tos}^{22}$

Otra infección que se puede diseminar o emerger como un problema de salud es la fiebre amarilla, que junto al fenómeno de movimiento de poblaciones se suma otro fenómeno como es el cambio climático de la región, que hace que se presenten casos en zonas geográficas que hasta hace algunos años era impensable que ello ocurriera. Otro ejemplo de ello es el dengue que se ha presentado como brotes aislados en el norte de Chile y en Isla de Pascua.

\section{La atención del niño inmigrante. ¿Está Chile preparado?}

Actualmente, este es uno de los grandes retos de los pediatras en el país. Cada vez es más frecuente la atención médica de niños nacidos en el extranjero o hijos de padres inmigrantes con condiciones de salud y costumbres diferentes.

Las patologías de los niños y adolescentes inmigrantes abarcan un amplio abanico de trastornos, muchos de ellos relacionados con la precaria situación en que generalmente han vivido y que en muchos casos se prolongan cuando llegan al país de destino.

Entre las enfermedades importadas, las infecciones constituyen uno de los capítulos que más preocupan al pediatra y al médico general que atiende niños. Nos podemos encontrar con infecciones emergentes y re-emergentes, que por la poca experiencia en las mismas, se tiende a cometer equivocaciones en el diagnóstico y tratamiento. Aunque el hecho de ser inmigrante no supone un riesgo mayor para tener una enfermedad diferente a la del país receptor, también es cierto que generalmente existen condiciones socioeconómicas desfavorables, que pueden tener una carga genética diferente que los hace propensos a ciertas enfermedades como por ejemplo: talasemias, anemia de células falciformes, etc ${ }^{16}$. Todo esto debe hacer 
Tabla 1. Patologías infecciosas prevalentes en el niño inmigrante

\begin{tabular}{lll}
\hline & Frecuentes & Menos frecuentes \\
\hline África & $\begin{array}{l}\text { TBC, Hepatitis, ITS, }{ }^{*} \text { VIH, } \\
\text { parásitos intestinales, } \\
\text { filariasis, paludismo }\end{array}$ & $\begin{array}{l}\text { Meningitis meningocócica, cólera, peste, fiebres virales hemorrágicas, } \\
\text { lepra, esquistosomiasis, estrongiloidiasis, cisticercosis, leishmania y } \\
\text { enfermedad del sueño }\end{array}$ \\
Latinoamérica & TBC, hepatitis y cisticercosis & $\begin{array}{l}\text { Meningitis meningocócica, cólera, fiebres virales hemorrágicas } \\
\text { (dengue), lepra, ITS*, VIH, parásitos intestinales, estrongiloidiasis, } \\
\text { paludismo, leishmaniasis y enfermedad de Chagas }\end{array}$ \\
& & $\begin{array}{l}\text { Meningitis meningocócica, cólera, peste, fiebres virales hemorrágicas, } \\
\text { lepra, ITS*, VIH, parásitos intestinales, esquistosomiasis, estrongiloi- } \\
\text { diasis, filariasis hemolinfáticas, paludismo, cisticercosis y leishmaniasis }\end{array}$ \\
Europa del Este & TBC, hepatitis & \\
& cisticercosis y leishmaniasis & \\
\hline
\end{tabular}

*Infecciones de Transmisión Sexual. Adaptado de: Vázquez VJ. Medicina de Familia 2000.

pensar que en la atención de estos niños debemos incluir preguntas dirigidas a detectar la presencia de ciertas enfermedades, verificar colocación de vacunas PAI y conocer antecedentes epidemiológicos a cerca de enfermedades prevalentes en el país de origen (tabla $1)^{23,24}$.

\section{Principales aspectos a tener en cuenta en el control de salud de un niño inmigrante:}

1. Lugar de nacimiento del niño y de sus padres.

2. Fecha de llegada al país.

3. Evaluación nutricional.

4. Evaluar la situación de vacunación. Completar el esquema en caso de retraso o ausencia de vacunas del Programa Ampliado de Inmunizaciones del país receptor.

5. Diagnosticar el problema de salud por el que acude.

6. Detectar otros problemas de salud no percibidos por la familia.

7. Incluir al niño en los programas de control sano.

8. Evaluación de problemas psicológicos y de integración.

\section{Conclusiones}

El incremento de las migraciones es un fenómeno mundial, que dentro de América Lati- na, Chile sobresale por ser un país en el cual el número de extranjeros ha tenido un aumento muy importante en los últimos 5 años, principalmente provenientes de países como Perú, Argentina, Bolivia, Ecuador y Colombia y más recientemente de Palestina.

La llegada de extranjeros al país no implica per se un riesgo mayor de un cambio en la epidemiología local, en la medida que los programas de vigilancia epidemiológica funcionen correctamente y que el personal de salud que atiende a pacientes inmigrantes estén alerta a la detección de ciertas patologías poco comunes o desconocidas en el país.

Podemos vernos enfrentados a enfermedades desconocidas en Chile como por ejemplo la anemia de células falciformes en inmigrantes de raza negra, otras hemoglobinopatías, etc, para lo cual nos debemos preparar.

Otras enfermedades que están en vías de erradicación en Chile, como la tuberculosis, podrían mostrar una detención en el ritmo de decrecimiento de la tasa por 100000 habitantes, como se ha podido documentar en el año 2007 con una cifra que no ha variado en 2 años, siendo que venía con una tendencia sostenida en disminución.

La invitación es a abrir la mente a conocer eventuales nuevas enfermedades y afrontar el reto de la atención de una nueva sociedad que incluye diferentes etnias con costumbres y condiciones de salud diferentes. 


\section{Referencias}

1.- Leakey LS: Homo habilis, Homo erectus and the Australopithecines. Nature 1966; 209(5030): 127981.

2.- Gushulak B, MacPherson D: Globalization of Infectious Diseases: The impact of migration. CID 2004; 38: 1742-8.

3.- La convención de las Naciones Unidas sobre los derechos de los migrantes: www.unesco.org/migration/ convention. 2003: 1- 12.

4.- Informe IOM: International Organization for Migration. www.iom.int

5.- CEPAL: Informe de la Comisión Económica para América Latina y el Caribe, 2003.

6.- Migración. Censo Poblacional 2002 Chile. www.censo2002.cl

7.- Vargas CN: Mortalidad infantil, Chile 1994. Rev Chil Pediatr 1996; 67: 6-9.

8.- Donoso SE: Descenso de la natalidad en Chile: Un problema país. Rev Chil Obstet Ginecol 2007; 72: 73-5.

9.- Cortez $A$ : Niños y niñas inmigrantes en Chile: derechos y realidades. Santiago, Chile: Fundación Anide/ Colectivo Sin Fronteras, 2004: 179.

10.- Decreto Ley 18.649 regula el ejercicio del derecho constitucional a la protección de la salud y crea un régimen de prestaciones de salud; publicada el 23 de noviembre de 1985. República de Chile.

11.- CIPER: Centro de Investigación e Información Periodística. Los efectos del "perdonazo migratorio": salud pública espera más de 30 mil nuevos usuarios. 4 de Enero 2008. www.ciperchile.cl/2008/01/04/.

12.- OIM-Organización Internacional para las Migraciones: Seminario "Migración y salud en Chile". Diciembre de 2008. www.oimconosur.org/notas/buscador.php? nota $=716$.
13.- Decreto Ley 1.094 Establece normas sobre extranjeros; publicada el 19 de julio de 1975. República de Chile.

14.- Ministerio de Salud: Programa TBC. Comunicación personal. 2008.

15.- Vargas CN, Quezada LA: Epidemiología, nueva morbilidad pediátrica y rol del pediatra. Rev Chi Pediatr 2007; 78: 103-10.

16.- Vallés X, Sánchez F, Panella H, García de Olalla P, Jansá JM, Caylá JA: TBC importada: una enfermedad emergente en países industrializados. Med Clin (Barc) 2002; 118: 376-8.

17.- Watkins RE, Plant AJ: Predicting tuberculosisamong migrant groups. Epidemiol Infect 2002; 129: 623-8.

18.- McPherson ME, Kelly H, Patel M, Leslie D: Persistent risk of tuberculosis in migrants a decade after arrival in Australia. MJA 2008; 188: 528-31.

19.- Perone SA, Bovier P, Pichonnaz Ch, Rochat T, Loutan $L$ : Tuberculosis in undocumented migrants, Geneva (letter). Emerg Infect Dis 2005; 11: 351-2.

20.- Desgupta K, Menzies D: Cost-effectiveness of tuberculosis control strategies among immigrants and refugees. Eur Respir J 2005; 25: 1107-16.

21.- Zhong-Wei Jia, Yun-Xi Liu, Christopher Dye, et al: Spatial Anallysis of tuberculosis cases in migrants and permanent residents, Beijing, 2000-2006. EID 2008; 14: 1413-20.

22.- Bastian I, Rigouts L, Van Deun A, Portaels F: Drectly observed treatment, short-course strategy and multidrugs-resistant tuberculosis: are any modifications required?. Bullet of The WHO 2000; 78: 238-51.

23.- Vázquez VJ, Galindo PJP, Luján JR: Atención inicial al paciente inmigrante en atención primaria. Medicina de Familia 2000; 1: 50-6.

24.- Atención al niño de origen extranjero. Área 11. Atención Primaria Instituto Madrileño de la Salud. 2001. www.aepap.org/inmigrante/area11.pdf 